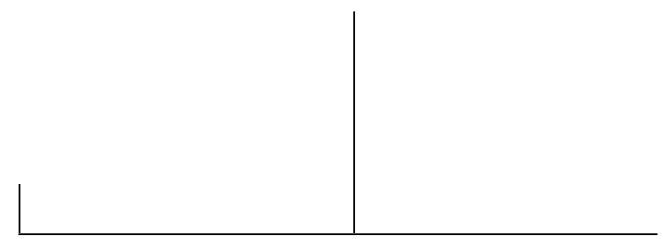

Rev. Latinoam. Psicopat. Fund., São Paulo, 16(1), 116-125, mar. 2013

\title{
Embriaguez e males da alma: entre a mania e a melancolia*
}

Paulo José Carvalho da Silva

Este artigo examina as relações estabelecidas no campo da medicina da alma entre a embriaguez e os males da alma. Parte da atitude ambivalente em relação ao vinho sustentada desde a Antiguidade para mostrar como no século XVIII explicações baseadas nas dinâmicas psicofisiológicas e tratamentos que faziam apelo à ordenação da razão com a vontade para o domínio dos apetites são substituídos por uma concepção propriamente patologizante do abuso da bebida.

Palavras-chave: Embriaguez, males da alma, loucura, dietética, melancolia

"Pesquisa realizada com apoio do Conselho Nacional de Desenvolvimento Científico e Tecnológico - CNPq (Brasília, DF, Br) (Bolsa de Produtividade em Pesquisa). 
Henrique Carneiro (2010) mostra que, apesar do alcoolismo ser um sério problema de saúde pública, a embriaguez é uma experiência reveladora de muitos aspectos da alma humana, como a busca pela intensidade, pelo transbordamento ou por inspiração. Uma história dos discursos sobre a embriaguez é mais do que uma história das bebidas ou mesmo do corpo ébrio, é uma história dos excessos e dos cuidados de si, da intimidade e das relações sociais, exigindo o cruzamento de fontes da medicina, da filosofia e da religião.

Sempre conforme Carneiro (2010) são múltiplas as conotações e as valorações dadas às bebidas inebriantes ao longo da história da cultura, cujos discursos e atitudes podem grosso modo ser organizados numa tensão entre os ideais de abstinência, excesso e temperança, desde os rituais dionisíacos aos extremos do higienismo do século XX. Em acordo com sua tese, este artigo, por sua vez, explora algumas ambivalências de discursos sobre a bebida em sua relação específica com os males da alma, em especial a melancolia e a mania, focando em fontes da medicina da alma, sobretudo, luso-brasileiras, como parte de um projeto maior de estudos dos males da alma na cultura de língua portuguesa.

O Problema $X X X$, atribuído ao filósofo Aristóteles, já estabelece uma analogia entre o estado temporário de embriaguez pelo consumo do vinho e os efeitos do humor melancólico na experiência de uma grande variedade de sensações, afetos e estados excepcionais. Entretanto, de modo geral, a qualidade quente do vinho teria o poder de causar um estado mais comparável a uma temporária mania, estimulando a audácia, os ardores amorosos e a ira, estados passionais opostos à melancolia, compleição psicofísica dos poetas e filósofos, na qual predominam a frieza e a secura. Inclusive, como também assinala Carneiro (2010), dentre um enorme número de estudos que não cabe aqui retomar, a tradição fundada neste comentário filosófico admite que o ex- 
cesso de calor artificial provocado pelo vinho poderia, ao fim da euforia que acompanha o estado de embriaguez, precipitar os melancólicos ao desânimo e ao suicídio.

Referência fundamental da medicina antiga, Galeno (129-199) afirma que a experiência cotidiana provaria que o vinho ameniza as tristezas e os abatimentos. Se em excesso enlouquece e faz até o sábio dizer o que teria preferido calar, leva ao delírio, à perda da memória e até à tristeza e ao desânimo dos melancólicos, tomado com moderação, o vinho, por meio da boa distribuição dos sucos corporais e da nutrição, afeta positivamente a alma, tornando-a mais amena e corajosa.

Esta noção antiga sobre o duplo efeito da embriaguez continua a marcar o pensamento médico ao longo da Idade Média, como atesta o capítulo dedicado à mesma do Medicina espiritual, do médico e filósofo árabe Razes (865-923), cujos tratados foram amplamente traduzidos para o latim e para o hebreu. Razes admite a conveniência da bebida nas circunstâncias em que se tem necessidade de uma distração das preocupações, de um pouco de coragem, audácia ou ímpeto. Por outro lado, pode ser muito inconveniente nas circunstâncias que pedem reflexão, clareza e calma. O problema reside justamente no fato de que a embriaguez reforçaria a alma desejante e a alma colérica ao mesmo tempo em que enfraqueceria a alma racional, sendo, por isso, uma das maiores ocasiões para a paixão e uma das maiores calamidades para o intelecto. Em busca do prazer, quem bebe do vinho em excesso sofre uma perda da função intelectual, da noção de pudor e da discrição, revelando seus segredos.

As múltiplas propriedades medicinais atribuídas ao vinho foram largamente divulgadas em escritos de médicos medievais, ainda muito influentes no limiar da Idade Moderna. Tanto é que o membro da Escola médica de Montpellier, Arnaldo de Villanova (1235-1311) dedica um tratado inteiro ao tema, o Liber de vinis, no qual prescreve várias receitas de vinhos, preparados com ervas e especiarias, para um número enorme de enfermidades, inclusive para a melancolia, passível de ser temperada com um líquido de qualidade quente.

No Leal Conselheiro, o rei médico de almas Dom Duarte (1391-1438) mostra-se, por sua vez, muito reticente ao uso medicinal do vinho. Ele mesmo afirma ter recusado quando os médicos lhe ofereceram vinho durante sua longa e grave crise melancólica (Carvalho da Silva, 2007). Para Dom Duarte, mais vale o regimento da vontade, isto é, o governo de si, do que as virtudes medicinais da bebida:

E deve teer, na voontade, firme propósito que por doença, idade, mudamento de compreissom, nom beva muito vinho, nem pouco auguado, mas que, per otras guisas, suas infirmidades se possam curar e el seer trazido a boo esforço e ledice e saúde, mes nunca per remedio de vinho, ao qual ponha regra 
de que se nom parta, salvo se for per grande necessidade. (Dom Duarte, 1438?/ 1998, p. 126)

Partindo do pressuposto que se deve comer e beber para viver e não o contrário, não se deixando dominar pelo alimento e pela bebida, o regime defendido por Dom Duarte prevê, em nome da saúde da alma e do corpo, o bom decoro à mesa, o respeito ao calendário religioso dos jejuns, a parcimônia no consumo do vinho (com duas partes de água), enfim, a moderação, mesmo numa mesa abundante (Carvalho da Silva, 2012). Em suma, os "gargantões" devem procurar moderar o apetite de alimentos e, sobretudo, de bebidas, sob o risco de precipitar-se na decadência física, moral e mesmo econômica.

A potência do vinho em, conforme o uso, desempenhar função importante na dietética e ser indicado para tratar a melancolia ou causar a loucura continua a ser um lugar comum em escritos da primeira modernidade. O grande humanista Marsilio Ficino (1433-1499) ratifica o valor nutritivo do bom vinho e afirma, no livro primeiro do De vita, que enquanto o vinho denso e escuro aumenta os sucos corporais melancólicos, nada lhes é mais indicado do que um "vinho leve, límpido, claro, fragrante", remetendo-se a Platão e a Aristóteles. Afinal, tal vinho aportaria a umidade e o calor que o melancólico tanto carece. Entretanto, Ficino recomenda um uso moderado pois, em excesso, seria muito prejudicial à saúde. Em suas palavras: "Sem dúvida se o vinho é em excesso ou muito quente e forte, enche a cabeça de humores e vapores pesados. Sem contar que a embriaguez torna louco e discorde (Ficino, 1489/1995, pp. 110-111).

Erasmo de Rotterdam (1467-1536) também aproxima loucura e embriaguez no Elogio da loucura: a personificação da própria afirma ter tido entre suas amas de leite a Embriaguez, filha de Baco, que permanece sua companheira e seguidora. Também afirma, entretanto, oferecer os mesmos alívios das preocupações, inquietações e sofrimentos, mas de modo mais permanente, como se a tal da boa loucura fosse um inebriamento contínuo. Ou, em outras palavras, ambos funcionariam como um antídoto para a repressão disciplinar perpetrada em nome da razão e para as agruras da condição humana.

Na Alemanha do século XVI, o consumo de bebidas alcoólicas era profundamente arraigado na cultura popular e mesmo no ambiente universitário. $\mathrm{O}$ fato das fontes de água serem, com frequência, muito poluídas não colaborava a favor das campanhas dos médicos e pastores contra os excessos, mesmo quando estes enfatizavam os graves sintomas do alcoolismo, na direção de uma falência completa das funções corporais, aliás, muito próxima da melancolia (Rieche, 2007). Seguindo a tradição medieval, aparentemente difundida por toda a Europa, algumas taças de vinho eram igualmente prescritas como tratamento ou mesmo consolação. O próprio Martinho Lutero recomendava aos aflitos o consumo 
moderado de vinhos leves, além de outros remédios naturais, como boa comida, companhia agradável, exercícios e música (Midelfort, 1999).

Cena, pelo visto, muito presente, o comportamento do embriagado feria sobremaneira os padrões de civilidade do Renascimento italiano. O ideal do cortesão previa que o mesmo exercitasse virtudes políticas e intelectuais como a prudência e a discrição, implícitas na noção de dignidade. Assim, qualquer excesso que se manifestasse numa deformação do corpo, das palavras e dos modos ultrapassava os limites do ideal de beleza, elegância e delicadeza que orientava as ações dignas do cortesão, sobretudo no que definia a convivência agradável no palácio.

A afetação maníaca do bêbado bem como o afã do glutão eram tidos como obviamente condenáveis, pois destoavam da perfeita harmonia nos hábitos, adquirida pelo senso da medida e pelo domínio dos apetites, louvada segundo o código da racionalidade de corte sistematizado por Baldassare Castiglione (1478-1529) em Il libro del cortegiano, em oposição à rudeza do campônio inculto:

Não quero seguir dizendo coisas demasiado notórias, como que o nosso cortesão não deve ostentar ser um grande comilão, nem beberrão, nem dissoluto em algum mau costume, nem sujo e desordenado no viver, com certos hábitos de camponês que lembram a enxada e o arado a mil milhas de distância. (Castiglione, 1528/1997, p. 126)

Embebedar-se não era privilégio dos ricos e seus banquetes desmedidos. Era também a distração e ruína dos miseráveis. É o que ilustra a pequena peça Pranto de Maria Parda, do primeiro grande dramaturgo da língua portuguesa Gil Vicente (1465?-1536?). Nela, Maria Parda vaga pelas ruas de Lisboa implorando aos taberneiros por um pouco de vinho, bebida que não pode pagar. Estes não apenas recusam a vender o vinho fiado, como também lhe passam lições de moral, incluindo-se o conselho que mate com água a secura. Triste, desventurada e sedenta, decide morrer, não sem antes redigir um testamento para os amantes da bebida:

A minha alma encomendo a Noé e a outrem não, e meu corpo enterrarão onde estão sempre bebendo. Leixo por minha herdeira e também testamenteira, Lianor Mendes de Arruda, que vendeu como sesuda, por beber, at'à peneira. Item mais mando levar por tochas cepas de vinha, e uma borracha minha com que hajam de encensar, porque teve malvasia. Encensem-me assi vazia, pois também eu assi vou; e a sede que me matou, venha pola claresia. (Vicente, 1522/1951, pp. 238-239)

$\mathrm{O}$ aspecto repugnante, grotesco ou simplesmente ridículo do bêbado aparece nas crônicas satíricas da vida na colônia escritas por Gregório de Matos (1633?1669?). Há desde relatos do abuso popular da aguardente aos excessos do con- 
sumo do vinho pela elite. Os efeitos nas relações ou na vida dos próximos também não ficam de fora. Por exemplo, o quanto sofre a esposa do alcoolista:

Coitada de quem/teve tal marido, que bebe o vestido. (...) Melhor me tivera/meu Pai encerrada, num canto fechada/melhor estivera, e não conhecera, quem me há de beber! (...) Darei um pregão: sabia todo mundo, que é poço sem fundo/ este Beberrão: com tal condição/ há de já morrer. Mofina mulher, que tão mal casou! Ai que se lá vou/ hei-vos de moer. (Matos, 1992, pp. 875-876)

No século XVIII, os discursos sobre a bebida e a embriaguez apresentam continuidades e descontinuidades. O médico do rei D. João V, Francisco da Fonseca Henriquez (1665-1731), dedica uma seção inteira de seu Âncora Medicinal para conservar a vida em saúde às bebidas alimentares e medicamentosas consumidas nos Setecentos. Dando continuidade à tradição humoral, defende que a água "rebate o furor da cólera" e "recreia a alma", mas mantém uma posição bastante reticente às virtudes nutritivas do vinho. De modo geral, considera que bebidas como a cerveja, os destilados e os vinhos mais fortes podem ser prejudiciais à saúde mental ou, em suas palavras, "ofendem a cabeça e os nervos", expressão empregada repetidamente nesta parte de sua dieta. Em particular, sobre os vinhos envelhecidos, escreve:

Uns e outros ofendem a cabeça e os nervos, causam sede, destemperam as entranhas, excitam cólicas ictéricas, secam o corpo e embebedam com facilidade. Fazem grandes danos em naturezas quentes, em que não se devem conceder, senão muito diluídos; e em naturezas frias só se devem usar mais como medicamento do que como alimento, porque, além de fazerem os referidos males, nutrem tão pouco que quase ficam fora da classe dos alimentos. (Henriquez, 1721/2004, pp. 234-235)

O médico enfatiza que a bebida perturba o entendimento e o bom uso da razão: "E não só causa estes incômodos do corpo, mas também ofende a alma bebendo-se com excesso, porque perturba a luz da razão, excita a ira e precipita os homens a atos torpes e libidinosos" (pp. 234-235).

Por outro lado, sua posição é mais positiva em relação ao uso moderado da sidra, o vinho de maçã produzido na Normandia. Segundo o médico, além de estar relacionada à longevidade, ela "conforta o estômago, alegra o coração, umedece muito, adoça os humores acres e mordazes e é útil nas afecções hipocondríacas, melancólicas e escorbúticas" (p. 258).

Henriquez mostra uma predileção pelo uso das bebidas não alcoólicas, introduzidas nas mesas europeias na Idade Moderna. Sobre o chocolate, de propriedade quente, afirma que "favorece o sistema nervoso" e "restaura as forças, vigora as entranhas e alenta o corpo todo", entre outras virtudes. O chá também tem muitos usos medicinais, dos quais se pode destacar que "é útil nas queixas 
dos nervos" e "conforta a memória", além de combater o sono. Assim como o café que, além de ser bom para os "males da cabeça" e da memória, "alegra o ânimo" e serviria de remédio para variadas doenças, inclusive, para a hipocondria.

Já conforme a Medicina Theologica, do porta-voz do organicismo iluminista no Brasil, o médico mineiro Francisco de Melo Franco (1757-1822), o consumo do vinho é mais prejudicial do que medicinal: "É para se lamentar que o vinho, sendo na Medicina um excelente remédio para curar muitas enfermidades, venha ele mesmo a ser por seu abuso um grande veneno, que mata a muitos depois de os fazer gemer com mil enfermidades" (p. 121).

Louvado entre os antigos por prolongar a vida, conservar a saúde e estimular as faculdades mentais e os sentidos, segundo Melo Franco, o vinho e outros licores em excesso enfraquecem e matam. A embriaguez causa uma estupidez e uma inércia das funções do espírito que pode durar vários dias ou mesmo por toda a vida. O maior problema, com efeito, é a constatação que a "bebedice" é uma grande enfermidade que nunca se cura com remédios morais, deixando impotente o médico de almas tradicional:

É sem dúvida nocivo o abuso do vinho e mais licores espirituosos; nem é preciso mais para persuadir aos senhores confessores de ser a bebedice uma enfermidade, do que lembrarem-se eles mesmos da prostração de forças com que ficam os que se encheram de algum licor. (Franco, 1794/1994, p. 123)

Ao condenar o abuso, Melo Franco até parece inserir-se na antiga tradição do cuidado de si orientado pela temperança. Entretanto, ao defender que a "bebedice" é uma patologia, Melo Franco inverte a explicação tradicional que via no excesso uma causa de enfermidades, considerando-a uma enfermidade em si mesma. E, sobretudo, assevera que sua compreensão e seu tratamento são exclusividades da medicina dos nervos e, portanto, do médico. Assim, as explicações baseadas nas dinâmicas psicofisiológicas e os tratamentos que faziam apelo à ordenação da razão com a vontade para o domínio dos apetites e formação de uma segunda natureza por meio do exercício dos bons hábitos seriam tão infundados quanto inúteis.

Os discursos antigos, com todos seus preconceitos morais e estéticos, aproximavam os efeitos da bebida aos sintomas das perturbações da alma. Particularmente, em sua ambivalência ou confusão, acabavam mostrando o quanto mania e melancolia estão relacionadas. Seriam condições humorais que não apenas podem se alternar, mas que também respondem a outra questão, secreta, da ordem da vida passional. Talvez a mesma questão que se revela na experiência da embriaguez, mas que não se reduz à mesma: uma sede que água não mata.

Para a ciência especializada, o problema não reside mais no líquido em si, que em pequena quantidade, ajustada convenientemente à compleição do organis- 
mo, podia ser um remédio e em excesso, ou em desacordo com as qualidades do corpo do bebedor, um veneno. Também não está no sujeito bebedor, que saberia dosar o que lhe convém ou seria impotente frente o poder liberador, consolador, antipathos da bebida. Trata-se não mais de um bom ou mau hábito, mas de uma patologia que, na exclusão teórica de uma atenção particular à história do sujeito que bebe, ganha autonomia e destaque na tendência médica que marcará o campo até os tempos atuais.

\section{Referências}

Aristóteles (2003). Problèmes. Sections XXVIII-XXXVIII. (P. Louis, trad.). Paris: Les Belles Lettres.

Carneiro, H. (2010). Bebida, abstinência e temperança na história antiga e moderna. São Paulo: Senac.

Carvalho da Silva, P. J. (2007, dez.). Do príncipe triste ao rei médico de almas. Revista Latinoamericana de Psicopatologia Fundamental, São Paulo, X(4), 696-710.

Carvalho da Silva, P. J. (2012). Alimentação e males da alma em fontes do período moderno. Filosofia e História da Biologia, 7(2), 305-316.

Castiglione, B. (1997). O cortesão. (C. N. M. Louzada, trad.). São Paulo: Martins Fontes. Erasmus, D. (1998). Elogio da loucura. (A. Ribeiro, trad.). Lisboa: Guimarães.

Ficino, M. (1995). Sulla Vita. Milano: Rusconi.

Franco, F. M. (1994). Medicina Theologica. São Paulo: Editora Giordano.

Galeno, C. (1995). L'âme et ses passions. Les passions et les erreurs de l'âme. Les âmes suivent les tempéraments du corps. (V. Barras, T. Birchler, A-F. Morand, trad. e notas). Paris: Les Belles Lettres.

Henriquez, F. F. (2004). Âncora medicinal para conservar a vida em saúde. São Paulo: Ateliê Editorial.

Matos, G. (1992). Obra poética. (v. II. J. Amado, ed.). Rio de Janeiro: Record.

Midelfort, E. H. C. (1999). A History of Madness in Sixteenth-Century Germany. Stanford: Stanford University Press.

Razi (2003). La médecine spirituelle (R. Brague, présentation et traduction). Paris: Flammarion.

Rieche, J. (2007). Literatur im Melancholiediskurs des 16. Jarhunderts. Volksprachige Medizin, Astrologie, Theologie und Michael Lindeners "Katzipori" (1558). Stuttgart: Hirzel Verlag.

Vicente, G. (1951). Pranto de Maria Parda. Obras completas de Gil Vicente (v. VI, pp. 227-243). Lisboa: Livraria Sá da Costa.

Villanova, A. (1943). The earliest printed book on wine (H. E. Sigerist, trad.). New York: Schuman's. 


\section{Resumos}

(Drunkenness and evils of the soul: between mania and melancholia)

This article examines the relationships established in the field of medicine of the soul between drunkenness and mental illness. The article shows how the ambivalent attitude toward wine, evident since antiquity and based on psychophysiological dynamics and treatments that appeal to the power of reason and will over the appetites, was replaced during the eighteenth century by the pathologic notion of alcohol abuse.

Key words: Drunkenness, mental illness, madness, diet, melancholy

(L'ivresse et les maux de l'âme: entre la manie et la mélancolie)

Cet article examine les rapports établis entre l'ivresse et les maux de l'âme dans le domaine de la médecine de l'âme. Il part de l'attitude ambivalente à l'égard du vin, existante dès l'antiquité, pour montrer de quelle façon, au XVIIIe siècle, les explications basées sur la dynamique psycho-physiologique et les traitements qui faisaient appel au règlement de la raison par la volonté pour maîtriser les appétits sont remplacés par une conception qui considère l'abus de l'alcool comme pathologique.

Mots clés: Ivresse, maux de l'âme, folie, diététique, mélancolie

(Embriaguez y los males del alma: entre la mania y la melancolia)

Este artículo examina las relaciones que se establecieron en el campo de la medicina del alma entre la embriaguez y los males del alma. A partir de la actitud ambivalente en relación al vino sostenida desde la antiguedad muestra como en el siglo XVIII las explicaciones basadas en la dinámicas psicofisiológicas y en los tratamientos que apelaban para el dominio de los apetitos por la ordenación de la razón por medio de la voluntad son substituídos, de hecho, por una concepción patologizante del abuso de la bebida.

Palabras clave: Embriaguez, males del alma, locura, dietética, melancolia

(Trunkenheit und Seelenleiden: zwischen Manie und Melancholie)

Dieser Artikel untersucht die im Bereich der Seelenmedizin festgelegten Beziehungen zwischen Trunkenheit und Seelenleiden. Ausgangspunkt der Studie ist die ambivalenten Einstellung zum Wein, die seit der Antike aufrecht gehalten wurde, um zu zeigen, wie im 18. Jahrhundert Erläuterungen, basierend auf psychophysiologischen Dynamiken, und Behandlungsweisen, die sich auf das Gebot der Vernunft beriefen und dem Verlangen, die Lust zu dominieren, durch eine sogenannte patologisierende Konzeption des Alkoholmissbrauchs ersetzt wurde.

Schlüsselwörter: Trunkenheit, Seelenleiden, Wahnsinn, Diätetik, Melancholie 
Citação/Citation: Carvalho da Silva, P. J. (2013, mar). Embriaguez e males da alma: entre a mania e a melancolia. Revista Latinoamericana de Psicopatologia Fundamental, São Paulo, 16(1), 116-125.

Editor do artigo/Editor: Prof. Dr. Paulo José Carvalho da Silva

Recebido/Received: 15.1.2013 / 1.15.2013 Aceito/Accepted: 30.1.2013 / 1.30.2013

Copyright: (C) 2009 Associação Universitária de Pesquisa em Psicopatologia Fundamental/ University Association for Research in Fundamental Psychopathology. Este é um artigo de livre acesso, que permite uso irrestrito, distribuição e reprodução em qualquer meio, desde que o autor e a fonte sejam citados / This is an open-access article, which permits unrestricted use, distribution, and reproduction in any medium, provided the original author and source are credited.

Financiamento/Funding: Esta pesquisa é financiada pelo Conselho Nacional de Desenvolvimento Científico e Tecnológico - CNPq / This research is funded by the Conselho Nacional de Desenvolvimento Científico e Tecnológico - CNPq.

Conflito de interesses/Conflict of interest: $\mathrm{O}$ autor declara que não há conflito de interesses / The author declares that has no conflict of interest.

\section{Paulo José Carvalho da Silva}

Psicólogo, psicanalista, mestre em História da Ciência pela Pontifícia Universidade Católica de São Paulo - PUC-SP; doutor em Psicologia pela Universidade de São Paulo - USP (São Paulo, SP, Br); professor doutor da Faculdade de Psicologia da PUC-SP (São Paulo, SP, Br); membro da Associação Universitária de Pesquisa em Psicopatologia Fundamental (São Paulo, $\mathrm{SP}, \mathrm{Br})$.

Rua Monte Alegre, 984

05015-901 São Paulo, SP, Brasil

Fone: (11) 99248-9202

e-mail: paulojcs@hotmail.com 